\title{
Long term measurements of submicrometer urban aerosols: statistical analysis for correlations with meteorological conditions and trace gases
}

\author{
B. Wehner and A. Wiedensohler \\ Institute for Tropospheric Research, Permoserstr. 15, 04318 Leipzig, Germany \\ Received: 27 August 2002 - Published in Atmos. Chem. Phys. Discuss.: 28 October 2002 \\ Revised: 13 June 2003 - Accepted: 17 June 2003 - Published: 24 June 2003
}

\begin{abstract}
Long-term measurements (over 4 years) of particle number size distributions (submicrometer particles, 3$800 \mathrm{~nm}$ in diameter), trace gases $\left(\mathrm{NO}, \mathrm{NO}_{2}\right.$, and $\left.\mathrm{O}_{3}\right)$, and meteorological parameters (global radiation, wind speed and direction, atmospheric pressure, etc.) were taken in a moderately polluted site in the city of Leipzig (Germany). The resulting complex data set was analyzed with respect to seasonal, weekly, and diurnal variation of the submicrometer aerosol. Car traffic produced a peak in the number size distribution at around $20 \mathrm{~nm}$ particle diameter during morning rush hour on weekdays. A second peak at $10-15 \mathrm{~nm}$ particle diameter occurred around noon during summer, confirmed by high correlation between concentration of particles less than $20 \mathrm{~nm}$ and the global radiation. This new-particle formation at noon was correlated with the amount of global radiation. A high concentration of accumulation mode particles (between 100 and $800 \mathrm{~nm}$ ), which are associated with large particle-surface area, might prevent this formation. Such high particle concentration in the ultrafine region (particles smaller than $20 \mathrm{~nm}$ in diameter) was not detected in the particle mass, and thus, particle mass concentration is not suitable for determining the diurnal patterns of particles. In summer, statistical time series analysis showed a cyclic pattern of ultrafine particles with a period of one day and confirmed the correlation with global radiation. Principal component analysis (PCA) revealed a strong correlation between the particle concentration for $20-800 \mathrm{~nm}$ particles and the NO- and $\mathrm{NO}_{2}$-concentrations, indicating the influence of combustion processes on this broad size range, in particular during winter. In addition, PCA also revealed that particle concentration depended on meteorological conditions such as wind speed and wind direction, although the dependence differed with particle size class.
\end{abstract}

Correspondence to: B. Wehner (birgit@ tropos.de)

\section{Introduction}

The effects of air pollution on human health are of great concern. In particular, aerosol particles less than $100 \mathrm{~nm}$ in diameter are suspected to increase the risk of respiratory and cardiovasculary diseases (e.g. Peters et al., 1997). Various epidemiological studies have investigated the effect of aerosol particles on human health. Pope and Dockery (1999) summarized more than 100 of such studies, and divided the studies into two categories: acute exposure studies and chronic exposure studies. Acute exposure studies look at short-term changes (usually 1-5 days) in human health measures associated with short-term changes in air pollution. Chronic exposure studies look at long-term changes (1-5 years) and compare various health states and different levels of pollution, and thus require long-term (more than 1 year) size-resolved particle measurements.

Particle concentrations in the urban atmosphere have been measured by several research groups, focusing predominantly on the total particle mass (e.g. Zee etal., 1998; Kuhlbusch et al., 1998; Roorda-Knape et al., 1998). The importance of fine particles (particles smaller than $100 \mathrm{~nm}$ in diameter) has been, however, neglected due to their small mass. Number size distributions have been measured using size spectrometers, but were limited to a size range $>10-20 \mathrm{~nm}$ (e.g. Tuch et al., 1997; Wichmann et al., 2000; Hughes et al., 1998; Buzorius et al., 1999) and most measurements were taken over shorter time periods (usually less than 1 year). Total number concentrations of particles down to $3 \mathrm{~nm}$ in diameter were measured (e.g. Väkevä et al., 1999; Harrison et al., 1999), but no information about the size distribution was obtained. Woo et al. (2001) measured number size distributions down to $3 \mathrm{~nm}$ in the urban area of Atlanta over a 13-month time period. Wåhlin et al. (2001) focused on traffic-related emissions by measuring particle size distributions in the size range 10 to $700 \mathrm{~nm}$ at three different sites in Copenhagen over a less than 2-month time period. 
Obtaining representative aerosol particle data for a certain geographical region requires long-term measurements, which can eliminate anomalies caused by variations in meteorological and regional conditions. Such data are suitable for correlation with epidemiological data and represent valuable input parameters for climate models.

Long-term measurements of number size distributions of particles between 3 and $800 \mathrm{~nm}$ in diameter with high size resolution were taken at a moderately polluted site in the urban area of Leipzig (urban background), a city of 460000 inhabitants, Germany, over a 4-year period (February 1997 to February 2001) (Wehner, 2000). Measurements also included meteorological and trace gas measurements. The resulting data set is complex, and therefore, detection of relationships among the measured parameters requires an indepth analysis that includes statistical methods such as correlation analysis and principal component analysis. Here, this analysis was done to characterize urban background aerosol by determining seasonal, weekly, and diurnal variation (see Sect. 3.1) and to find relations between the measured parameters (see Sect. 3.5).

\section{Measurements}

The long-term measurements were made on top of the building of the Institute for Tropospheric Research (IfT), which is located on the outskirts of Leipzig. The research complex itself is surrounded by several busy streets as well as by residential areas, but with no significant industrial particle sources nearby. This location is therefore influenced by several pollution sources, such as car traffic, domestic heating, small power and heating plants, and can be considered typical for moderately polluted regions in urban areas.

The inlets for aerosol and trace gas measurements were mounted on the roof of the building and were about $16 \mathrm{~m}$ above the ground to minimize the influence of local emission sources such as passing cars. The instruments for aerosol and trace gas measurements were operated inside the IfT at room-temperature conditions. Meteorological measurements were taken on a platform on the roof of the same building.

Number size distributions were measured in the particle size range $3<D_{p}<800 \mathrm{~nm}$ by a Twin Differential Mobility Particle Sizer (TDMPS) system (designed by Birmili et al., 1999) comprising two size spectrometers that simultaneously measure different particle size ranges at dry conditions. Nucleation mode particles $\left(3<D_{p}<22 \mathrm{~nm}\right.$ ) were measured by an Ultrafine Differential Mobility Analyzer (Hauke type) in conjunction with an Ultrafine Condensation Particle Counter (UCPC, Model 3025, TSI Inc., St. Paul, MN, USA). Particles in the range from $22<D_{p}<800 \mathrm{~nm}$ were measured using a Differential Mobility Analyzer (Hauke type) and a CPC (Model 3010, TSI Inc., St. Paul, MN, USA).
Table 1. Instruments for trace gas, meteorological, and aerosol measurements at the IfT-building

\begin{tabular}{|c|c|}
\hline Parameter & Instrument /Manufacturer \\
\hline $\mathrm{O}_{3}$ & $\begin{array}{l}\text { Ozone-Analyser, model } 8810 \\
\text { Monitor Labs Inc., } \\
\text { Englewood (CO), USA }\end{array}$ \\
\hline $\mathrm{NO}, \mathrm{NO}_{2}$ & $\begin{array}{l}\mathrm{NO} / \mathrm{NO}_{2}-\text { Analyser, model } 8841 \\
\text { Monitor Labs Inc., } \\
\text { Englewood (CO), USA }\end{array}$ \\
\hline $\mathrm{SO}_{2}$ & $\begin{array}{l}\mathrm{SO}_{2} \text {-Analyser, model AF } 21 \mathrm{M} \\
\text { Ansyco Inc., Karlsruhe, D }\end{array}$ \\
\hline $\mathrm{CO}$ & $\begin{array}{l}\text { CO-Analyser, model CO } 11 \mathrm{M} \\
\text { Ansyco Inc., Karlsruhe, D }\end{array}$ \\
\hline $\begin{array}{l}\text { Temperature } \\
\text { Relative Humidity } \\
\text { Atmospheric pressure } \\
\text { Wind speed } \\
\text { Wind direction } \\
\text { Precipitation }\end{array}$ & $\begin{array}{l}\text { Platinum thermometer Pt } 100 \\
\text { Hair hygrometer } \\
\text { Aneroid barometer } \\
\text { Cup anemometer } \\
\text { Wind vane } \\
\text { Ombrometer HP } \\
\text { Adolf-Thies GmbH } \\
\text { Klima- Mess- und Regeltechnik } \\
\text { Göttingen, D }\end{array}$ \\
\hline Global Radiation & $\begin{array}{l}\text { Pyranometer CM } 11 \\
\text { Kipp \& Zonen, Delft, NL }\end{array}$ \\
\hline $\begin{array}{l}\text { Number size distribution } \\
3<D_{p}<800 \mathrm{~nm}\end{array}$ & $\begin{array}{l}\text { Twin DMPS } \\
\text { IfT Leipzig (see text for details) }\end{array}$ \\
\hline
\end{tabular}

Trace gases and meteorological parameters (Table 1) were measured continuously at the same sampling point as the particle measurements.

Trace gas data had a time resolution of $1 \mathrm{~min}$, meteorological data had a 10-min time resolution, and DMPS-data had a 15-min time resolution. For data analysis chemical and meteorological measurements were transformed to a 15 -min time resolution. All measurement days (= less than one hour of data is missing) between 1997 and 2001 were used for this study. The data were divided into summer (June through August) and winter periods (December through February) and into different days of the week: weekdays, Saturday, and Sunday.

\section{Results and discussion}

\subsection{Mean variation of number size distributions and related parameters}

Diurnal patterns of number size distributions in different seasons were determined and compared for the four-year measurement period, thus reducing the influence of meteorological anomalies on the data reduction. Figure 1 shows the mean 


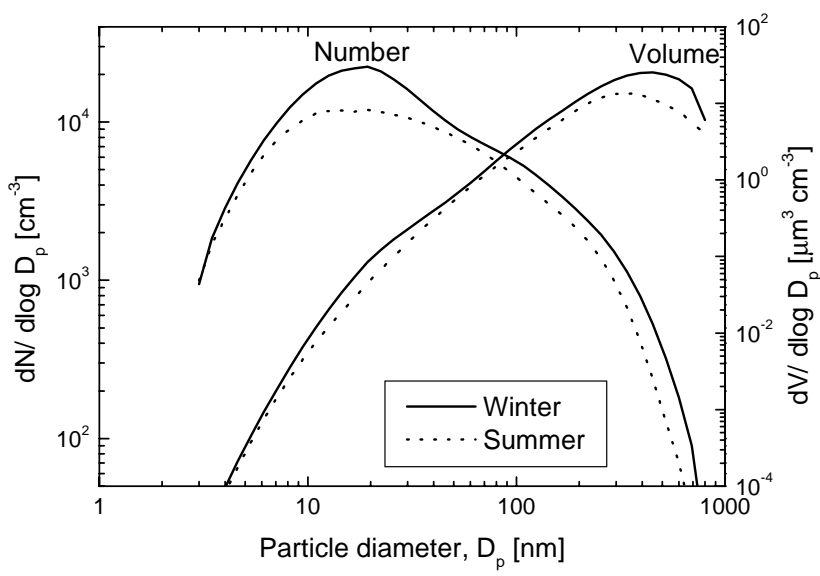

Fig. 1. Mean number and volume size distributions averaged over summer and winter (1997-2001).

number and volume size distributions for summer and winter averaged over the 4-year period. The number concentrations were higher in winter than in summer. The maximum concentration for both seasons occurred for a particle size between 10 and $20 \mathrm{~nm}$. The maximum number concentration in winter was two times higher than in summer due to higher emissions caused by heating processes and to a less intensive vertical mixing and the corresponding dilution. The volume size distribution was calculated from the measured number size distribution, assuming spherical particles. The maximum of the volume size distribution occurred at a particle size around $300 \mathrm{~nm}$ for winter, and around $400 \mathrm{~nm}$ for summer, and the maximal difference occurred at $600 \mathrm{~nm}$ and was a factor of over three. The particle volume concentration in the ultrafine range at $20 \mathrm{~nm}$ exceeded that of summer by a factor of two, although the absolute values were more than two orders of magnitude less than those at around $500 \mathrm{~nm}$.

Figure 2 and 3 show the diurnal cycle of particle number size distributions in winter and summer averaged over weekdays, Saturdays, and Sundays.

On weekdays, the peak number concentration in winter occurred in the size range around $20 \mathrm{~nm}$ during the morning hours (see Fig. 2a). This corresponds with higher traffic density. On Saturdays (Fig. 2b), peaks occurred irregularly in the range between 15 and $20 \mathrm{~nm}$ over the entire day. On Sundays, the number concentration was the lowest of the week, probably due to lower traffic density. On Sundays, peaks occurred not only during the day, but also in the early morning (Saturday night activities) and late evening (homeward travellers).

On weekdays in summer (Fig. 3a) the particle concentration increased in the early morning hours, peaking between 7:00 and 8:00 at a particle diameter around $20 \mathrm{~nm}$, and then peaking again at noon. The second peak was at a higher concentration, but at a lower particle diameter, $10-15 \mathrm{~nm}$. This second peak corresponds well with the the typical di-

\section{Winter 1997-2001}
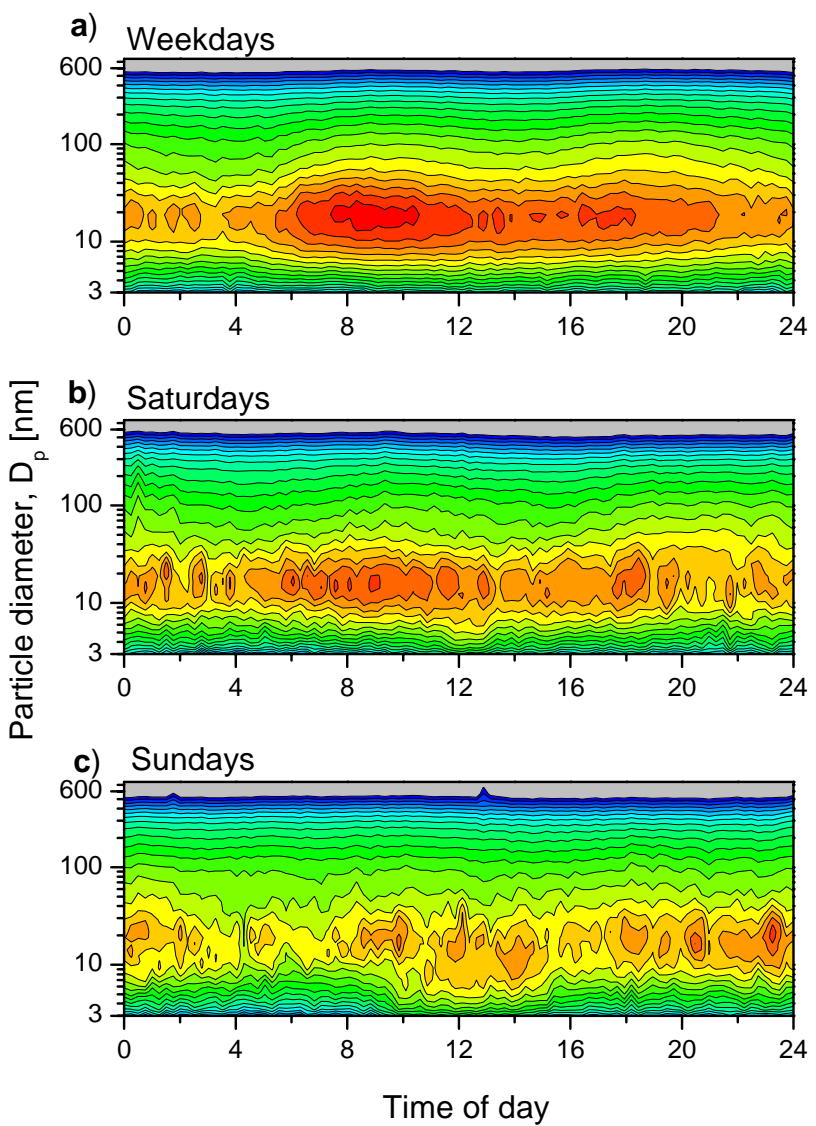

Fig. 2. Winter diurnal variation in the number size distribution averaged over (a) weekdays, (b) Saturdays, and (c) Sundays (December-February; 1997-2001). The colors represent the number concentration as $\mathrm{dN} / \mathrm{d} \log \mathrm{D}_{p}$ with grey as the lower limit corresponding to $<200 \mathrm{~cm}^{-3}$ and red as the maximum corresponding to $45000 \mathrm{~cm}^{-3}$.

urnal peak global radiation, indicating that the small particles were produced by photochemically induced nucleation of gaseous components. Between 13:00 and 15:00 this peak concentration was relatively stable. After 15:00, the number of small particles decreased, concurrent with the typically decreasing global radiation leading to less production of new particles and thus the concentration of existing particles decreased by coagulation. Compared with the morning rush hour, the evening rush hour was barely recognizable. After 18:00, the mean particle diameter of the size distribution increased. On Saturdays, no rush-hour peak occurred, but the concentration was still higher than that on Sundays due to traffic to the downtown area on Saturday morning. Again, the nucleation peak (10-15 nm) around noon was clearly pronounced, in particular on Saturdays. The peak concentration was roughly the same as that on weekdays. Thus, this phenomenon occurs independently of the day of the week an 

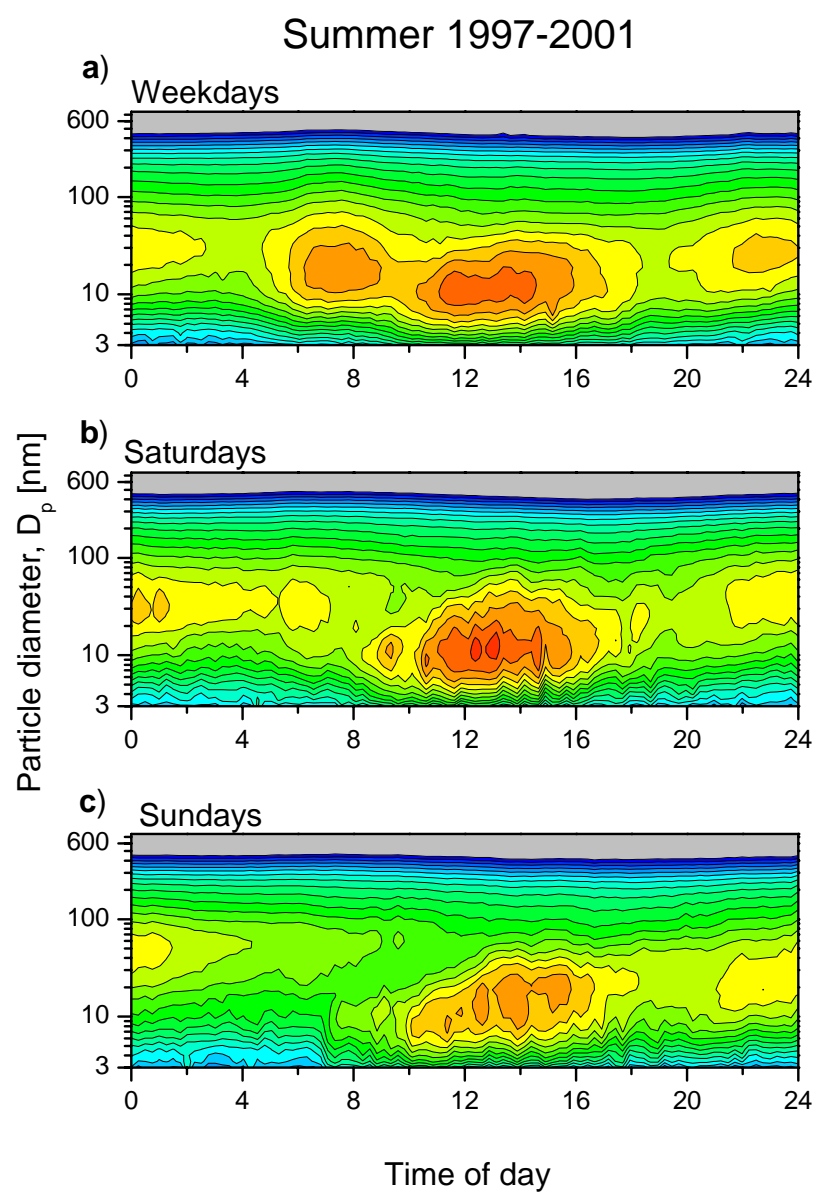

Fig. 3. Summer diurnal variation in the number size distribution averaged over (a) weekdays, (b) Saturdays, and (c) Sundays (June-August; 1997-2001). The colors represent the number concentration as $\mathrm{dN} / \mathrm{d} \log \mathrm{D}_{p}$ with grey as the lower limit corresponding to $<200 \mathrm{~cm}^{-3}$ and red as the maximum corresponding to $45000 \mathrm{~cm}^{-3}$.

concentration of potential precursor gases was always high enough in this urban area. In winter, the formation of new particles was not observed (evidenced by the lack of a nucleation peak around noon in Fig. 2), because of much lower global radiation and a higher surface-area concentration.

Application of number size distributions to numerical models requires to approximate them with a mathematical function which reduces the number of distribution parameters to a minimum while maintaining the salient features of the distribution. The mathematical representation of the size distribution is very important and categorizes the aerosol simulation techniques as discrete, spline, sectional, modal, or monodisperse (Whitby and McMurry, 1997). One possibility is to represent the size distribution by distinct populations, which are called "modes". They could be described completely by their total particle number, mean diameter and shape. The most popular function for this purpose is the log- normal distribution usually formulated as (e.g. Heintzenberg, 1994):

$\frac{d N}{d \log D_{p}}=\frac{N_{t}}{\sqrt{2 \pi} \log \sigma} \exp \left(-\frac{\left(\log D_{p}-\log \bar{D}_{p}\right)^{2}}{2(\log \sigma)^{2}}\right)$

with $N_{t}$ being the total number concentration of the mode, $\bar{D}_{p}$ the number-median diameter, and $\sigma$ being the geometric mean standard deviation of the distribution. In this study, log means always $\log _{10}$.

The complete data set should be expressed as well as possible by a small number of parameters. Therefore, a number of necessary size distributions was determined empirically. The data were divided again into summer and winter as well as Sunday and Weekday and by the hour of day. For the last point the day was divided into four groups: night (22:00-06:00), morning (06:00-10:00), day (10:00-16:00), and evening (16:00-22:00). Table 2 contains the parameters of lognormal modes representing the averaged size distributions of the four-year data set.

The measured number size distributions can be used to calculate the total number, surface area, and volume concentrations within the observed size range, assuming spherical particles. These calculations were done for all number size distributions divided into summer and winter, and into weekdays, and Sundays. Saturday pattern were a mixture of weekday and Sunday patterns, and therefore, for clarity, not shown here.

Figure 4a shows the diurnal variation in the total number concentration on weekdays and Sundays in summer and winter. The mean concentrations on weekdays were significantly higher in winter than in summer, and dominated by a peak in the morning at around 08:00 (difference in the concentrations in summer and winter was almost a factor of two) and by a less pronounced peak in the late afternoon (17:00-18:00). One reason for the higher morning maximum in winter may be the lower temperatures leading to higher supersaturation of the emitted gases, followed by higher nucleation rates, and as a second point less vertical mixing in the lower atmosphere compared to summer days. In summer, the morning rush hour was clearly recognizable between 06:00 and 08:00; however, the second peak at noon was slightly more pronounced. On Sundays, peaks occurred between 10:00 and 18:00.

The diurnal variation in the volume concentration on weekdays (cf. Fig. 4b) again clearly shows the rush-hour peaks. The new particle formation around noon in summer was not evident in the volume concentration, neither on weekdays nor on Sundays. The reason is that new particles are small $(10-15 \mathrm{~nm})$, and therefore their contribution to the particle volume is negligible. The volume concentration in winter was significantly higher than that in summer, independent of the time of the day or the day of the week. In general, the variation in volume concentration during the day was much weaker than that in the number concentration, 
Table 2. Fit parameter of lognormal modes describing the mean size distributions measured at the IfT, while $N_{t}$ is given in particle number $\mathrm{cm}^{-3}$ and $\bar{D}_{p}$ in $\mathrm{nm}$

\begin{tabular}{l|rrr|rrr|rrr}
\hline Parameter & $N_{t} 1$ & $\sigma 1$ & $\bar{D}_{p} 1$ & $N_{t} 2$ & $\sigma 2$ & $\bar{D}_{p} 2$ & $N_{t} 3$ & $\sigma 3$ & $\bar{D}_{p} 3$ \\
\hline Winter Weekdays & & & & & & & & \\
\hline night & 2100 & 1.58 & 205 & 5100 & 1.72 & 61 & 16300 & 1.91 & 16 \\
morning & 1700 & 1.58 & 227 & 8200 & 1.96 & 55 & 32000 & 1.79 & 16 \\
day & 2200 & 1.59 & 207 & 7900 & 1.73 & 60 & 28600 & 1.83 & 15 \\
evening & 2200 & 1.61 & 199 & 8500 & 1.79 & 61 & 24600 & 1.83 & 16 \\
\hline Winter Sundays & & & & & & & & \\
\hline night & 1600 & 1.56 & 218 & 6100 & 1.83 & 61 & 14600 & 1.85 & 15 \\
morning & 1800 & 1.61 & 205 & 5800 & 1.79 & 61 & 11500 & 1.84 & 15 \\
day & 1800 & 1.60 & 207 & 6300 & 1.77 & 60 & 15100 & 1.92 & 12 \\
evening & 1500 & 1.53 & 216 & 5700 & 1.81 & 64 & 15000 & 1.90 & 15 \\
\hline Summer Weekdays & & & & & & & & \\
\hline night & 1100 & 1.61 & 209 & 6300 & 1.80 & 60 & 8800 & 2.00 & 18 \\
morning & 600 & 1.65 & 227 & 7800 & 2.02 & 57 & 15100 & 1.98 & 15 \\
day & 500 & 1.54 & 230 & 4600 & 2.01 & 65 & 19900 & 2.03 & 12 \\
evening & 400 & 1.62 & 220 & 4600 & 1.97 & 68 & 10600 & 2.07 & 15 \\
\hline \multicolumn{2}{l}{ Summer Sundays } & & & & & & & & \\
\hline night & 900 & 1.52 & 236 & 7200 & 1.82 & 60 & 5200 & 2.03 & 16 \\
morning & 1200 & 1.59 & 201 & 6300 & 1.84 & 56 & 4900 & 2.00 & 10 \\
day & 1200 & 1.52 & 215 & 5000 & 1.83 & 50 & 14800 & 1.90 & 12 \\
evening & 1100 & 1.62 & 180 & 6300 & 1.98 & 39 & 7200 & 1.95 & 11 \\
\hline
\end{tabular}

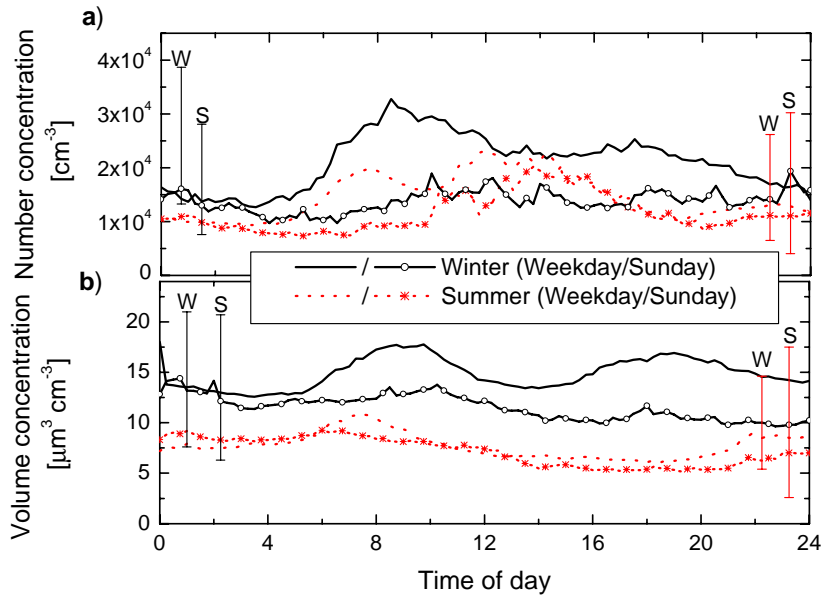

Fig. 4. Mean diurnal variation in total number concentration and total volume concentration on weekdays and Sundays in summer and winter and corresponding maximum 95\%-confidence level (w = weekday, $\mathrm{s}=$ sunday).

indicating that, unlike particle number, volume is not influenced by short fluctuations in emission sources.

Mean values of number concentration for the size classes are given in Table 3 as well as the relative contribution of the size classes to the total number concentration. In winter, $\mathrm{N}_{10-20}$ dominates significantly the number concentration. In summer, the influence of $\mathrm{N}_{3}-10$ increases and reaches for Sundays a similar value than $\mathrm{N}_{10-20}$. With increasing diameters the relative contribution decreases.

A significant long-term trend in particle concentration was not recognizable: the total particle number concentration shows an increase of $1.7 \pm 1.1 \mathrm{~cm}^{-3} \mathrm{~d}^{-1}$ (Standard error). The corresponding mean value was $16634 \mathrm{~cm}^{-3}$ with a $95 \%$ confidence level of \pm 505 .

\subsection{Statistical investigation}

\subsubsection{Methods}

Mean values were used to show, for example, variation of number size distributions (see Sect. 3.1), but they are not suitable to find relationships between variables within complex data sets. Various analysis techniques can be used on the long-term measurements in Leipzig to reveal the underlying deterministic behavior, and thus help clarify cause and effect relationships in environmental problems. Time series analysis of other pollution data include studies by Salcedo et al. (1999); Lam et al. (1999); Iverson (1989); Morawska et al. (1998); Simpson (1992). Findings from those studies include high correlation among $\mathrm{PM}_{10}, \mathrm{PM}_{2.5}$, and $\mathrm{NO}_{2}$ (Lam et al., 1999), good correlation among $\mathrm{CO}, \mathrm{NO} / \mathrm{NO}_{2}$, and $\mathrm{PM}_{10}$ (Morawska et al., 1998), and a strong influence of motor vehicle emissions on $\mathrm{PM}_{10}$ (Simpson, 1992). 
Table 3. Mean number concentrations of the total size range $\left(\mathrm{N}_{t o t}\right)$ and size fractions $\mathrm{N}_{3-10}-\mathrm{N}_{100-800}$ as defined above and relative contribution of the size fractions to the total number concentration for weekdays and Sundays in Winter and Summer

\begin{tabular}{rrrrrrrr} 
& $\mathbf{N}_{t o t}$ & $\mathbf{N}_{3-10}$ & $\mathbf{N}_{10-20}$ & $\mathbf{N}_{20-30}$ & $\mathbf{N}_{30-50}$ & $\mathbf{N}_{50-100}$ & $\mathbf{N}_{100-800}$ \\
\hline Winter: Weekdays & & & & & & & \\
Average [cm ${ }^{-3}$ ] & 21377 & 3520 & 6330 & 3814 & 3103 & 2496 & 2107 \\
rel. Contribution [\%] & & 16.5 & 29.6 & 17.8 & 14.5 & 11.7 & 9.9 \\
\hline $\begin{array}{r}\text { Winter: Sundays } \\
\quad \text { Average [cm }\end{array}$ ] & 14052 & 3075 & 3656 & 2071 & 1833 & 1772 & 1669 \\
rel. Contribution [\%] & & 21.9 & 26.0 & 14.7 & 13.1 & 12.6 & 11.9 \\
\hline Summer: Weekdays & & & & & & & \\
Average [cm ${ }^{-3}$ ] & 14728 & 3236 & 3868 & 2093 & 2225 & 2025 & 1383 \\
rel. Contribution [\%] & & 22.0 & 26.3 & 14.2 & 15.1 & 13.7 & 9.4 \\
\hline Summer: Sundays & & & & & & & \\
Average [cm ${ }^{-3}$ ] & 11596 & 2783 & 2746 & 1624 & 1760 & 1702 & 1199 \\
rel. Contribution [\%] & & 24.0 & 23.7 & 14.0 & 15.2 & 14.7 & 10.3 \\
\hline
\end{tabular}

Here, statistical time series analysis was applied to the complete data set. First, auto-correlation functions were calculated to reveal periodic behavior of single variables (e.g. particle number concentration in a certain size range) and to identify typical time scales. Then, cross-correlation functions were used to determine the correlation coefficient between two time series that were shifted by an increasing time lag.

Multivariate data analysis is a tool to investigate complex data sets containing numerous measured parameters by revealing trends and relationships among these parameters. Here, multivariate data analysis was applied to the Leipzig data set to identify sources of aerosol particles and to quantify their contribution to variation in the measured aerosol parameters. Although several multivariate data analysis techniques have been applied to atmospheric data (e.g. Hansson et al., 1984; Wolff et al., 1984; Wiedensohler et al., 1996; Swietlicki et al., 1996; Statheropoulos et al., 1998), Principal Component Analysis (PCA) is the most common, and therefore used here.

\subsubsection{Correlation analysis}

One major problem in analyzing a time series is understanding the periodic variations in the measured parameters. A time series is a superposition of cyclic variations with different amplitudes and random fluctuations. Correlation analysis is a suitable technique to identify these cyclic variations in the time domain.

The aim of correlation analysis is to investigate one or more time series of measured parameters (e.g. particle number concentration) and to calculate the correlation coefficient as a function of the time lag $\tau$. The methods are described in brief here (details are described in textbooks, such as Båth, 1974; Einax et al., 1997).
The correlation function used here is defined as (Einax et al., 1997)

$r_{x y}(\tau)=\frac{1}{n} \sum_{t=0}^{n} x(t) y(t+\tau)$

where $x$ and $y$ are identical (auto-correlation) or different (cross correlation) discrete functions of time (e.g. measured data), $n$ is the total number of data points included, and $\tau=k \cdot \Delta t$ with $k=0,1,2, \ldots$. The auto-correlation function yields its maximum at $\tau=0$. For auto-scaled values (mean $=0$, standard deviation $=1$ ) this maximum value is 1. The occurrence of a relative maximum of $r_{x x}(\tau)$ indicates cyclic variations with period $\tau$, whereas the value of $r_{x x}(\tau)$ yields the correlation coefficient for $\tau$.

Additionally, the correlation analysis yields another property of the time series, namely, the auto-correlation analysis also contains information about the persistence of a time series. This persistence indicates how much an individual measured value depends on the preceding values (von Storch and Zwiers, 1999).

A measure for this persistence is the integral time scale, $\tau_{\alpha}$, defined as (Tennekes and Lumley, 1974)

$\tau_{\alpha}=\int_{0}^{\infty} r_{x x}(\tau) d \tau$

Measured time series are always limited in time; therefore, Kaimal and Finnigan (1994) introduced $\tau_{\alpha}$ as an integral up to a designated value of $\tau$. One possibility is to choose $\tau_{0}$ to be the value at which the auto-correlation function becomes zero for the first time. Another approach is to integrate up to $\tau_{e}$, the value at which the auto-correlation function is decreased to $e^{-1}$. For $\tau \gg \tau_{\alpha}$ the data are statistically independent. The resulting $\tau_{\alpha}$ is a typical time to observe a change in the current variable. 


\subsubsection{Principal Component Analysis}

Large data sets usually contain a huge amount of information, which is often too complex for a straightforward interpretation. Principal Component Analysis (PCA) is a projection method that helps extract more information from a data set than when individual parameter analysis is used. The theoretical background is described in brief here (and described in detail in a variety of textbooks, e.g. Fahrmeir et al., 1996; Einax et al., 1997).

PCA is basically a data reduction technique. The aim is to find linear combinations of the original variables that account for as much of the total variance in the measured data as possible. The linear combinations fulfilling this condition are called Principal Components (PCs) and are by definition uncorrelated with each other. The first PC carries most of the information about the data (i.e. explains most of the variance in the data), the second one will then carry the maximum residual information, and so on. PCA is a special case of factor analysis that transforms the original set of intercorrelated variables into a set of uncorrelated variables.

The main result of PCA are factor loadings, which reflect how much the variable (e.g. particle number concentration $<10 \mathrm{~nm}$ ) contributes to that particular PC and how well that $\mathrm{PC}$ describes the variation of that certain variable.

The data set including the relevant variables listed in Table 2 was analyzed by PCA using commercial software (The Unscrambler, Version 6.1, Camo AS, Trondheim, NR). The results of the complete set of measurements and variables will be presented here, covering 80000 samples for each variable (e.g. particle number concentration $<10 \mathrm{~nm}$ ).

The PCA can also be applied to different numbers of variables. In particular, variables that are interdependent have to share their factor loadings if they all are included in the PCA. Examples of such well-correlated variables in the data set analyzed here are temperature, relative humidity, and global radiation. They are connected for several meteorological situations. The PCA would show this as a result but it would not give any new information to interpret particle measurements. Global radiation was identified to force new particle production (e.g. O’Dowd et al., 1999; Boy and Kulmala, 2002), and therefore were included in the PCA, whereas temperature and relative humidity were not included into the calculation presented below. Previous calculations showed no relevant correlation between humidity and other variables as discussed below. Including them gives mainly the result of their typical diurnal cycle of two anti-correlated variables such as temperature and relative humidity. Furthermore, to focus on more relevant parameters, such as wind direction, variables not apparently relevant for the interpretation (e.g. amount of precipitation) were also not included.
Table 4. Parameters for statistical analysis

\begin{tabular}{llc}
\hline Parameter & Symbol & Scaling method \\
\hline Particle concentration: & & \\
Number 3-10 nm & $\mathrm{N}_{3-10}$ & $\log 10$ \\
Number 10-20 nm & $\mathrm{N}_{10-20}$ & $\log 10$ \\
Number 20-30 nm & $\mathrm{N}_{20-30}$ & $\log 10$ \\
Number 30-50 nm & $\mathrm{N}_{30-50}$ & $\log 10$ \\
Number 50-100 nm & $\mathrm{N}_{50-100}$ & $\log 10$ \\
Number 100-800 nm & $\mathrm{N}_{100-800}$ & $\log 10$ \\
\hline \multicolumn{2}{c}{ Trace gas concentration } & \\
\hline $\mathrm{O}_{3}$ & $\mathrm{O}_{3}$ & sqrt \\
NO & $\mathrm{NO}$ & sqrt \\
NO & $\mathrm{NO}$ & sqrt \\
\hline \multicolumn{2}{c}{ Meteorological parameter } & \\
\hline Atmospheric pressure & $p$ & - \\
Global radiation & $Q$ & sqrt \\
Wind speed & $u$ & - \\
Wind: $x$-component & $u_{x}$ & - \\
Wind: $y$-component & $u_{y}$ &
\end{tabular}

\subsubsection{Data preparation for statistical analysis}

All but two of the measured parameters were directly analyzed without further manipulation. The first exception was particle concentrations in the different size ranges, resulting from integration of number size distributions over a certain size range. The number concentration between 3 and $10 \mathrm{~nm}$ in diameter is labelled $\mathrm{N}_{3-10}$ and so on (see Table 2). The other exception was wind direction, which is circular. The wind vector was therefore divided into a zonal $(x)$ and a meridional $(y)$ component. A positive $x$ component describes the east vector of the wind, and a positive $y$-component describes the north vector. All of the data (particle, trace gas, and meteorological) were divided into two different seasons (summer and winter) and different days of the week to find longer-term differences.

Only the trace gases that were clearly linked with particle concentration (e.g. for $\mathrm{SO}_{2}$ no correlation with particle concentration was found) were analyzed, and redundant data (e.g. $\mathrm{CO}$ and $\mathrm{NO}$ are both emitted by car traffic) in the entire data set were eliminated. Thus, particle number concentration for selected size classes, $\mathrm{O}_{3}^{-}, \mathrm{NO}-$ and $\mathrm{NO}_{2-}$ concentrations, atmospheric pressure, global radiation, wind speed, and wind direction (Table 4) were used for the statistical analysis. For the correlation analysis the time series were de-trended by using linear regression. For correlation analysis and PCA, all data were centered (i.e. average of resulting data set was 0 ) and then divided by the standard deviation, resulting in statistically equivalent weight variables. PCA variables with extreme dynamic ranges were scaled (using the method indicated in the last column in Table 2, and discussed in Sect. 3.5) to obtain a normal distribution of the input parameters. 


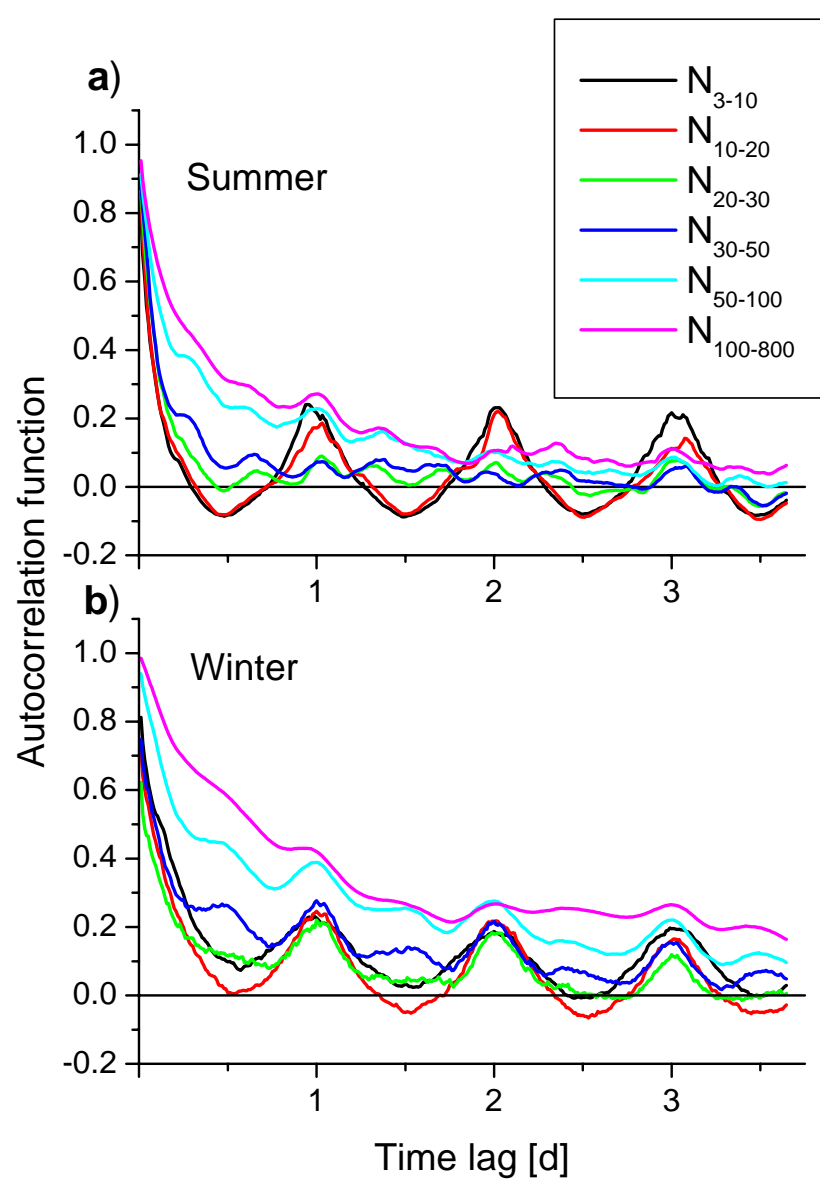

Fig. 5. Auto-correlation functions of different size classes calculated for weekdays in (a) summer and (b) winter.

\subsection{Results of auto-correlation}

Figure 5 shows auto-correlation functions calculated from measurements of the number size distributions limited to weekdays during summer and winter in 1997-2001. Results of weekends are not presented here, because they do not show this cyclic behavior of weekdays caused by a more irregularly traffic pattern on weekends.

In summer, particles less than $20 \mathrm{~nm}\left(\mathrm{~N}_{3-10}\right.$ and $\left.\mathrm{N}_{10-20}\right)$ showed a clear periodic behavior with a period of one day (peaks at multiples of 1 day). The relative maxima at time lags of $\frac{1}{2}$ day, $1 \frac{1}{2}$ day, etc., correspond to a negative correlation for these time lags. With increasing particle size, the peaks became less pronounced compared to these two smaller size classes $\left(\mathrm{N}_{3-10}\right.$ and $\left.\mathrm{N}_{10-20}\right)$. Thus, only small particles $\left(D_{p}<20 \mathrm{~nm}\right)$ showed a typical diurnal cycle.

In winter, particles between 3 and $50 \mathrm{~nm}\left(\mathrm{~N}_{3-10}-\mathrm{N}_{30-50}\right)$ in particular also clearly showed a cyclic behavior with a period of about 1 day. These size classes are strongly influenced by car traffic, and peaks in traffic emissions are cyclic. The correlation coefficients for winter decreased slower with time

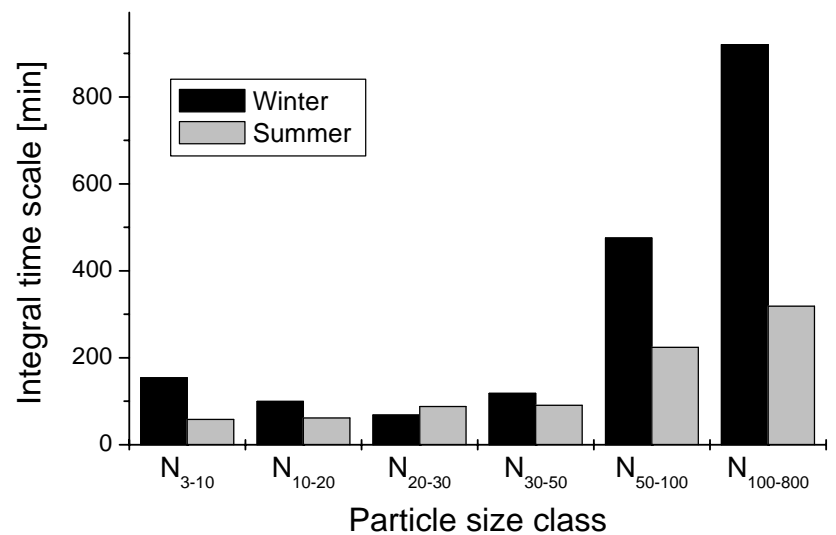

Fig. 6. Integral time scale calculated from the auto-correlation functions of particle size concentration classes for summer and winter.

lag than those for summer, indicating that the winter data were more interdependent due to slower variations caused by less vertical dilution.

As described above (Sect. 3.2.3), a measure of the persistence of a time series is the integral time scale $\tau_{\alpha}$, which could be calculated from the auto-correlation function. For this study, $\tau_{\alpha}$ was calculated by integrating the autocorrelation function up to $\tau_{\alpha}=\frac{1}{e}$ as recommended in Kaimal and Finnigan (1994). The integral time scale is a typical time for a variation in a certain variable.

The results are shown in Fig. 6 for the different particle size concentration classes. The minimum $\tau_{\alpha}$ for winter was approx. $70 \mathrm{~min}$ and occurred for particles between 20 and $30 \mathrm{~nm}\left(\mathrm{~N}_{20-30}\right)$, and that for summer was approx. $60 \mathrm{~min}$ and was for particles between 3 and $10 \mathrm{~nm}\left(\mathrm{~N}_{3-10}\right)$. That means typical changes in number concentration occur on a time scale of one hour and have its minimum in the size classes mentioned above. Typical $\tau_{\alpha}$ of these two particle size classes were around $60 \mathrm{~min}$, and their concentration changed with respect to time faster than that of other size classes. Particles between 20 and $30 \mathrm{~nm}\left(\mathrm{~N}_{20-30}\right)$ were mostly trafficrelated and changes in concentration occurred rapidly, depending on the traffic density, which is the dominant particle emission source in winter. Particles smaller than $20 \mathrm{~nm}$ $\left(\mathrm{N}_{3-10}\right.$ and $\left.\mathrm{N}_{10-20}\right)$ are predominantly produced by intensive global radiation. This production process caused the dominant variations seen in summer. In contrast, the concentration of larger particles (greater than $50 \mathrm{~nm} ; \mathrm{N}_{50-100}$ and $\mathrm{N}_{100-800}$ ) varied much slower, and their concentration depended predominantly on the air mass transported to the site. The typical $\tau_{\alpha}$ increased with increasing particle diameter from $30 \mathrm{~nm}$ to $800 \mathrm{~nm}$. The $\tau_{\alpha}$ differed significantly between summer and winter. For the largest particles $(100-800 \mathrm{~nm})$, $\tau_{\alpha}$ was $920 \mathrm{~min}$ (more than $15 \mathrm{~h}$ ) in winter, which is almost three times higher than that in summer (320 min). This difference was caused by differences in meteorological conditions between the two seasons; in winter, the stratification of the 


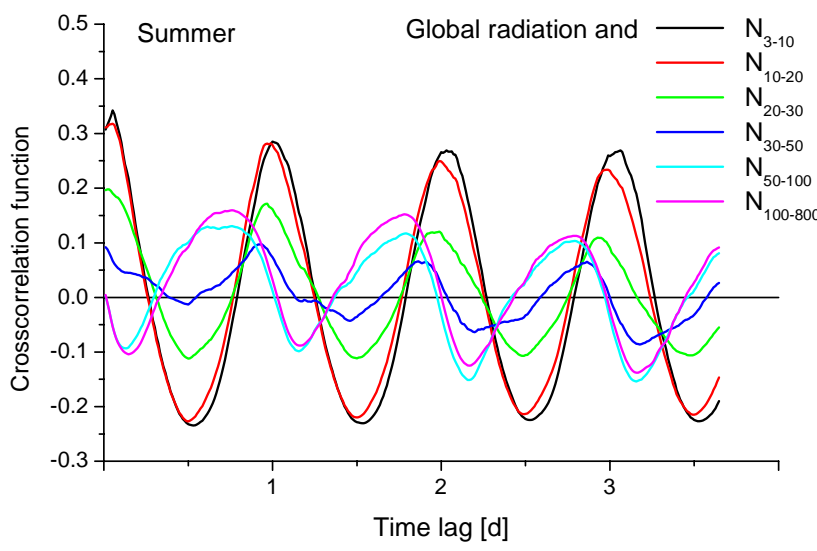

Fig. 7. Cross-correlation functions of different particle size classes and global radiation for weekdays in summer.

lowest part of the boundary layer that is relevant for groundbased measurements is stable more often than in summer, thus suppressing vertical dilution.

\subsection{Results of cross-correlation}

The time series of particle concentrations $\left(\mathrm{N}_{3-10}-\mathrm{N}_{100-800}\right)$ were correlated with all measured meteorological parameters and trace gases. However, only the key results showing clear correlations are presented here.

Figure 7 shows these cross-correlation functions between the time series of global radiation and particle concentration data for weekdays in summer.

Particles less than $20 \mathrm{~nm}\left(\mathrm{~N}_{3-10}\right.$ and $\left.\mathrm{N}_{10-20}\right)$ correlated well with the global radiation at a time lag of less than $1 \mathrm{~h}$, which is recognizable as the maximum $(>0.3)$ in the correlation curve. The global radiation as well as these small particles peaked around noon or one to two hours later within a cycle of $24 \mathrm{~h}$, reflected by relative peaks in the correlation coefficient at time lags of 1 day. The time series of particle concentration was shifted with respect to the global radiation, indicating that the global radiation peaked before the small-particle concentration peaked. This result confirms the hypothesis that small particles $\left(D_{p}<20 \mathrm{~nm}\right)$ are formed as a consequence of photochemical processes, which strongly depends on the intensity of global radiation (e.g. O'Dowd et al., 1999; Birmili et al., 2000).

For particles between 20 and $50 \mathrm{~nm}\left(\mathrm{~N}_{20-30}\right.$ and $\left.\mathrm{N}_{30-50}\right)$, the correlation coefficient was lower than that for particles less than $20 \mathrm{~nm}\left(\mathrm{~N}_{3-10}\right.$ and $\left.\mathrm{N}_{10-20}\right)$, and the peak for $N_{30-50}$ was shifted slightly to time lags of less than 1 day. This lower coefficient and slight shift indicate that the dependence between particle concentration and global radiation decreases with increasing particle diameter. A similar shift was also seen for particles larger than $50 \mathrm{~nm}\left(\mathrm{~N}_{50-100}\right.$ and $\mathrm{N}_{100-800}$ ); however, the maximum correlation coefficient was slightly higher for these two largest size classes com-

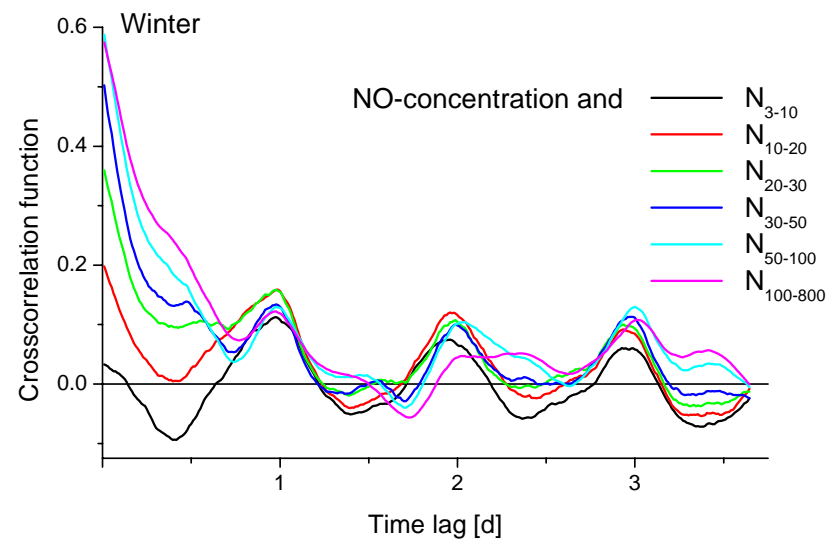

Fig. 8. Cross-correlation functions of different particle size classes and NO concentration on weekdays in winter.

pared with $\mathrm{N}_{30-50}$. The phase shift between the two time series (i.e. between global radiation and $\mathrm{N}_{50-100}$ or $\mathrm{N}_{100-800}$, respectively) was $16-18 \mathrm{~h}$. However, it is implausible that the radiation would influence large particles to such a long time lag; the higher particle concentration should rather be a result of the morning rush hour, other combustion processes, or boundary layer development and the corresponding dilution. At a time lag of zero, the correlation coefficient was also almost zero between the two largest size classes and the global radiation, indicating no direct relationship.

The NO concentration measured close to roads is known to be an indicator of car traffic emissions. Particle size classes influenced by car traffic should therefore correlate well with the NO concentration, and thus show no large time lag. Figure 8 shows the corresponding cross-correlation for winter. Particles larger than $30 \mathrm{~nm}\left(\mathrm{~N}_{30-50}-\mathrm{N}_{100-800}\right)$ showed correlation coefficients between 0.35 and 0.6 with the NO concentration at a time lag of zero. Only particles less than $10 \mathrm{~nm}\left(\mathrm{~N}_{3-10}\right)$ were nearly uncorrelated for a time lag of zero. After a lag of 1 day, $\mathrm{N}_{10-20}$ and $\mathrm{N}_{20-30}$ show the best correlation with NO $\left(r_{x y}=0.17\right.$ for $\mathrm{N}_{10-20}$ and $\mathrm{N}_{20-30}$; $r_{x y}=0.13$ for $\mathrm{N}_{30-50}$ and $\mathrm{N}_{50-100}$ ), indicating their cyclic behavior connected with car traffic. The weakest correlation was for particles greater than $100 \mathrm{~nm}$, and the next weakest was the fraction of these particles less than $10 \mathrm{~nm}$. These results correspond with the observed diurnal variation, where the particles between 10 and $100 \mathrm{~nm}$ are the most strongly influenced by car traffic and somewhat by domestic heating.

\subsection{Results of Principal Component Analysis (PCA)}

Table 5 lists the key results of the calculated PCA in terms of the (factor) loadings of the variables for the first three PCs. For easier interpretation, loadings with an absolute value greater than 0.25 (arbitrarily chosen as showing stronger correlation) are in bold face. The last row in the table gives the percentage of the variance in the data that can be explained 
Table 5. Factor loadings of PCA calculated with selected variables of winter and summer data, and the total variance explained (cumulative) by the individual PCs

\begin{tabular}{lrrrrrr}
\hline & \multicolumn{3}{c}{ (a) Winter only } & \multicolumn{3}{c}{ (b) Summer only } \\
\hline & PC 1 & PC 2 & PC 3 & PC 1 & PC 2 & PC 3 \\
\hline $\mathrm{N}_{3-10}$ & 0.04 & $\mathbf{0 . 5 7}$ & -0.15 & 0.09 & $\mathbf{0 . 5 1}$ & -0.18 \\
$\mathrm{~N}_{10-20}$ & 0.22 & $\mathbf{0 . 4 8}$ & -0.23 & $\mathbf{0 . 2 8}$ & $\mathbf{0 . 4 4}$ & -0.12 \\
$\mathrm{~N}_{20-30}$ & $\mathbf{0 . 3 3}$ & $\mathbf{0 . 2 9}$ & -0.07 & $\mathbf{0 . 3 9}$ & $\mathbf{0 . 2 6}$ & -0.00 \\
$\mathrm{~N}_{30-50}$ & $\mathbf{0 . 3 7}$ & 0.13 & 0.08 & $\mathbf{0 . 4 2}$ & 0.11 & 0.09 \\
$\mathrm{~N}_{50-100}$ & $\mathbf{0 . 3 8}$ & -0.04 & 0.20 & $\mathbf{0 . 4 0}$ & -0.05 & 0.23 \\
$\mathrm{~N}_{100-800}$ & $\mathbf{0 . 3 5}$ & -0.15 & 0.23 & $\mathbf{0 . 3 3}$ & -0.15 & $\mathbf{0 . 3 5}$ \\
\hline $\mathrm{O}_{3}$ & $\mathbf{- 0 . 3 1}$ & 0.22 & 0.22 & -0.19 & $\mathbf{0 . 2 8}$ & $\mathbf{0 . 4 8}$ \\
$\mathrm{NO}$ & $\mathbf{0 . 3 1}$ & 0.02 & 0.05 & $\mathbf{0 . 2 6}$ & -0.03 & $\mathbf{- 0 . 3 3}$ \\
$\mathrm{NO}_{2}$ & $\mathbf{0 . 3 3}$ & -0.10 & -0.04 & $\mathbf{0 . 3 2}$ & -0.21 & $\mathbf{- 0 . 2 6}$ \\
\hline$p$ & 0.14 & -0.13 & 0.19 & 0.09 & -0.02 & $\mathbf{0 . 3 3}$ \\
$Q$ & 0.02 & 0.23 & $\mathbf{0 . 8 1}$ & -0.02 & $\mathbf{0 . 4 0}$ & $\mathbf{0 . 2 7}$ \\
$u$ & $\mathbf{- 0 . 2 9}$ & 0.21 & 0.21 & $\mathbf{- 0 . 2 6}$ & $\mathbf{0 . 3 4}$ & -0.05 \\
$u_{x}$ & 0.17 & -0.05 & -0.16 & 0.17 & -0.18 & $\mathbf{0 . 3 4}$ \\
$u_{y}$ & 0.07 & $\mathbf{- 0 . 3 8}$ & 0.07 & -0.10 & -0.11 & $\mathbf{0 . 2 6}$ \\
\hline Explained & $39 \%$ & $54 \%$ & $60 \%$ & $26 \%$ & $41 \%$ & $51 \%$ \\
Variance & & & & & & \\
\hline
\end{tabular}

by the respective $\mathrm{PC}$ and the higher level PCs. For example, PC 1 explains $39 \%$ of the variance in the data for winter, and PC 1 and PC 2 combined explain 54\% of the variance. Because PC 1 to PC 3 explain a major part of the total variances ( $51 \%$ for summer and $60 \%$ for winter), PC 4 to 14 are not shown because of their relatively low explained variance.

To interpret the results, the first three individual PCs will be evaluated here.

\subsubsection{Principal Component 1}

In summer or winter, PC 1 (Table 5) showed the highest loadings for $\mathrm{N}_{20-30}-\mathrm{N}_{100-800}$ and also for $\mathrm{NO}$ and $\mathrm{NO}_{2}$, thus indicating a correlation between the particle number concentration in the range from $20-800 \mathrm{~nm}$ and the concentrations of $\mathrm{NO}$ and $\mathrm{NO}_{2}$. The $\mathrm{NO}$ and $\mathrm{NO}_{2}$ concentrations are indicators for combustion processes occurring in car engines, domestic stoves, and heating plants. Previously reported measurements at traffic-dominated sites found that the maximum number concentration occurred for diameters around $20 \mathrm{~nm}$ (e.g. Wehner et al., 2002). Vehicles directly emit significant numbers of particles in the size range between 40 and $100 \mathrm{~nm}$ (e.g. Maricq et al., 1999; Ristovski et al., 1998; Harris and Maricq, 2001). The concentration of particles greater than $100 \mathrm{~nm}\left(\mathrm{~N}_{100-800}\right)$, however, also showed high loadings ( 0.35 for winter and 0.33 for summer). PC 1 also represents emissions from other combustion processes such as heating plants and domestic stoves. The loading for the size class $\mathrm{N}_{3-10}$ (0.04 for winter and 0.09 for summer) indicates that these particles were not directly correlated. The significant negative correlation $(-0.31)$ with the $\mathrm{O}_{3}$ concentration can be explained by the chemical balance between $\mathrm{NO}_{x}$ and $\mathrm{O}_{3}$ leading to an anti-cyclical pattern of these species. The only meteorological parameter that showed remarkable loading for this PC is wind speed $u$. The loading of $u$ was negative, indicating that high particle concentrations were negatively correlated with wind speed. Thus, the effect of direct emissions is enhanced by low wind speeds that suppress the dilution of emissions with clean air.

Although the loadings for summer and winter were almost identical for PC 1 , the explained variance for the winter data $(39 \%)$ was higher than that for summer $(26 \%)$, clearly indicating a lower influence of combustion processes and a more rapid dilution of emitted particles in summer.

\subsubsection{Principal Component 2}

In winter, PC 2 showed high loadings in $\mathrm{N}_{3-10}-\mathrm{N}_{20-30}$ and a negative loading $(<0.25)$ in $u_{y}$, indicating that the smallest size fraction of particles $(<30 \mathrm{~nm})$ was correlated with wind directions from the south. This result is difficult to interpret because of the insignificant role of small particles during winter. In summer, PC 2 is also strongly correlated with the global radiation $Q$, the wind speed $u$, and the ozone concentration $\mathrm{O}_{3}$, thus indicating that the formation of new particles as well as ozone is enhanced by the intensity of global radiation and by higher wind speeds. This result agrees well with results in Fig. 3, with results from the correlation analysis (Sect. 3.4), and with previous studies (e.g. Weber et al., 1999; Boy and Kulmala, 2002). The new particles are formed as a consequence of photochemical reactions of gaseous species. This PC was slightly negatively correlated with $\mathrm{N}_{100-800}$ and positively correlated with $u$, thus indicating that new particle formation is forced when cleaner air is transported to the measurement site and emissions are diluted.

No information is yet available on where in the atmosphere the new particles are produced. Nilsson et al. (2001); Bigg (1997) and others hypothesized as follows that the formation occurs if two differently polluted layers are mixed by turbulent processes. On a summer day with intense global radiation, the depth of the mixed layer (ML) increases slowly after sunrise because of the strong nocturnal stable layer that caps the young ML. By late morning usually, the cool nocturnal air has been warmed to a temperature near that of the residual layer. Subsequently, the top of the ML will rise to the base of the residual layer. The ML will then grow rapidly and existing pollution will be vertically well mixed. New particles might also be formed when the new ML reaches the residual layer and the different air masses are mixed. This turbulent mixing of different air masses with different temperature, humidity, and gaseous compounds might lead to locally restricted nucleation events. This hypothesis and other possible formation mechanisms were discussed by Nilsson et al. (2001). In an urban atmosphere, the conditions are 
however more complex. Because particle formation within remote regions such as arctic or coastal environments is not understood yet, an explanation for urban environments is not yet feasible.

\subsubsection{Principal Component 3}

In winter, PC 3 showed a high loading only in the global radiation $Q$. In summer, the correlation with other variables was more significant. For example, PC 3 correlated with the concentration of large particles $\left(\mathrm{N}_{100-800}\right)$, ozone $\mathrm{O}_{3}$, atmospheric pressure $p$, wind directions $u_{x}$ and $u_{y}$, and global radiation $Q$ with loadings greater than 0.25 , but was negatively correlated with $\mathrm{NO}_{x}$ concentration. The combination of the positive loadings of $p, Q, u_{x}$, and $u_{y}$ describes the meteorological situation of a high pressure region over Eastern Europe connected with high global radiation and wind coming from the northeast. This meteorological situation usually leads to the advection of continental (polluted) air from Eastern Europe. Continental air usually contains higher concentrations of particles larger than $100 \mathrm{~nm}$ than does less polluted air masses, e.g. a marine air mass (Pueschel et al., 1986). Such a polluted air mass influenced by high global radiation enhances the ozone formation in an urban region followed by a decrease in $\mathrm{NO}_{x}$ concentration.

PC 3 was also slightly negatively correlated with $\mathrm{N}_{3-10}$, indicating a negative correlation between global radiation and the formation of new particles. However, PC 2 shows a positive correlation for these two parameters. Together, these correlations of these two PCs indicate that the occurrence of new particle production depends not only on the presence of intense global radiation but also on the properties of the present air mass. The presence of a high particle surface-area concentration prevents nucleation due to diffusion of small particles and condensed material to the surface of larger particles (e.g. Friedlander et al., 1991; Covert et al., 1992).

In winter, not all of these correlations were observed. The ozone concentration $O 3$ is correlated mainly with global radiation $Q$. Loadings of the other meteorological variables and $\mathrm{N}_{100-800}$ were smaller than those in summer due to the insignificant role of new particle formation and related processes in winter.

Assuming that the higher order PCs (4-14) contained only noise and therefore can be neglected, the $60 \%$ explained variance in winter and 51\% in summer by PC 1-PC 3 can be treated as the reasonable fraction of variance $(100 \%)$ excluding the noise. Thus, based on the assumption that these first three PCs explain $100 \%$ of the variance, PC 1 explains $65 \%$ of the variance in winter (39\% of $60 \%$ ) and $51 \%$ in summer, neglecting the noise. The identification of PC 1 as the contribution of combustion sources can be interpreted as $65 \%$ ( $51 \%$ in summer) of the submicrometer particles (diameter $<800 \mathrm{~nm}$ ) coming from fossil fuel combustion, such as power plants, vehicle engines, and domestic heating. Based on this $100 \%$ assumption, PC 2 explains $25 \%$ of the variance in winter (29\% in summer), thus indicating that new particle formation in connection with high global radiation contributes $25 \%$ in winter and $29 \%$ in summer, respectively, variance in the submicrometer aerosol. According to the PC 3 loading based on this $100 \%$ assumption, the advection of accumulation mode particles contributed about $10 \%$ in winter and $20 \%$ in summer to the number concentration of submicrometer aerosol.

Various model runs with nearly every combination of variables were performed. In particular, possible relations between new particle formation and humidity were investigated in more detail. The only result was that relative humidity showed a negative correlation with new particle formation in PC 2 due to the contrarian diurnal cycle of relative humidity and temperature/radiation. To eliminate this diurnal cycle, diurnal means were calculated and used for PCA. However, the result was the same, because radiation days with new particle formation are usually dryer that cloudy days. Additionally the absolute humidity was used for PCA, 15min-values as well as diurnal means but they did not show any clear correlation in summer again negative correlation. The only effect the usage of such connected variables, as temperature and relative humidity, has is that factor loadings decrease because they have to share their correlations. Therefore, variables without clear correlation with particle concentrations resulting from previous PCA runs were left out of the final calculation presented here.

\section{Summary and conclusions}

This study focused on a 4-year data set of particle number size distributions, trace gases, and meteorological parameters measured in the urban area of Leipzig (Germany).

The total number concentration in winter was generally higher, caused by increased particle emissions (e.g. from heating processes) and by different meteorological conditions suppressing vertical exchange (e.g. due to capping inversions). The peaks in concentration occurred at particle diameters between 20 and $30 \mathrm{~nm}$ and were linked to morning rush hour ( $\sim$ 08:00 on weekdays). In summer, a second peak around noon occurred at particle sizes around $10 \mathrm{~nm}$ on weekdays as well as on weekends, induced by photochemically induced production of new particles. This confirms that the concentration of anthropogenically emitted trace gases is not critical for particle formation in urban areas or that concentrations of these gases are always sufficiently high enough to trigger new particle formation.

Correlation analysis confirmed the typical diurnal cycle of particles less than $100 \mathrm{~nm}$ with a peak in the number concentration during the morning rush hour. Furthermore, time series of ultrafine particles $(<20 \mathrm{~nm})$ were well correlated with those of global radiation, particularly during summer. High correlations between the number concentration of particles 
larger than $20 \mathrm{~nm}$ and the NO concentration were found in winter, indicating that the occurrence of these particles is directly related to emissions from combustion processes.

Principal Component Analysis (PCA) confirmed that variations in the submicrometer aerosol (less than $1000 \mathrm{~nm}$ ) were mainly due to combustion processes, as indicated by high correlation between the concentrations of $\mathrm{NO}$ and $\mathrm{NO}_{2}$ and the number concentrations of particles between 20 and $800 \mathrm{~nm}$. Neglecting noise in the analysis, this correlation explains $65 \%$ of the total variance of the data in winter and $51 \%$ in summer. PCA clearly showed that the number concentration of accumulation mode particles (between 100 and $800 \mathrm{~nm}$ ) also strongly depended on the amount of direct emissions. A relationship between particles above $100 \mathrm{~nm}$ and traffic patterns was not recognizable without the use of statistical methods, due to the low number concentration of particles in this size range. Meteorological conditions significantly influence the particle concentrations, and thus possibly enhance the influence of a particle source; for example, under high pressure weather conditions during winter, the pollutants are often trapped below an inversion layer.

Especially during summer, the formation of new particles significantly influences the total number concentration. However, this influence is not completely understood at continental sites due to the complexity of the gaseous pollutants. Our statistical analysis of the Leipzig data confirmed the connection between periods of intense global radiation and the occurrence of small particles (less than $20 \mathrm{~nm}$ ) under the presence of a clean air mass (low concentration of particles smaller than $100 \mathrm{~nm}$ ). Detailed clarification of particle formation will require vertical profiles of meteorological parameters, to examine a possible connection with the development of a convective boundary layer that strongly depends on global radiation.

The results presented here provide a large, unique database that is characterized by particle number size distribution measurements down to $3 \mathrm{~nm}$. This study contains representative aerosol data for an urban area that are representable by simple modal parameters for the different seasons, days of the week, and times of day. This data set can provide valuable parameters for climate models to calculate the climate forcing of aerosol particles.

Moreover, the results of this long-term study are suitable for correlation with epidemiological data. Such a comparison might reveal the influence of the submicrometer particle concentration on respiratory diseases in urban areas more clearly than previous experiments that cover more narrow size ranges. The quality of epidemiological studies might be improved due to the high size resolution of the number size distributions and the long duration of the study. One of the next step will be to compare different measurement sites within one city and find out how representative one (this) site is.
Acknowledgements. The authors thank Anett Kappe for doing the trace gas measurements during the experiment and preparing the data for investigation, and thank Kerstin Flachowsky for providing meteorological data over the past few years. Thanks to Uta Schmieder and Katrin Lehmann for their help in data preparation.

\section{References}

Båth, M.: Spectral Analysis in Geophysics, pp. 563 , Elsevier Scientific, Amsterdam, 1974.

Bigg, E. K.: A mechanism for the formation of new particles in the atmosphere, Atmospheric research, 43, 129-137, 1997.

Birmili, W., Stratmann, F., and Wiedensohler, A.: Design of a DMA-based Size Spectrometer for large particle size range and stable operation, J. Aerosol Sci., 30, (4), 549-554, 1999.

Birmili, W. and Wiedensohler, A.: New particle formation in the continental boundary layer: Meteorological and gas phase parameter influence, Geophys. Res. Lett., 27, 3325-3328, 2000.

Boy, M. and Kulmala, M.: Nucleation events in the continental boundary layer: Influence of physical and meteorological parameters, Atmos. Chem. Phys., 2, 1-16, 2002.

Buzorius, G., Hämeri, K., Pekkanen, J., and Kulmala, M.: Spatial variation of aerosol number concentration in Helsinki city, Atmos. Environ., 33, 553-565, 1999.

Covert, D. S., Kapustin, V. N., Quinn, P. K., and Bates, T. S.: New Particle Formation in the Marine Boundary Layer, J. Geophys. Res., 97, D18, 20 581-20 589, 1992.

Einax, J. W., Zwanziger, H. W. and Geiss, S.: Chemometrics in Environmental Analysis, VCH Verlagsgesellschaft mbH, pp. 384, Weinheim, 1997.

Fahrmeir, L., Hamerle, A. and Tutz, G.: Multivariate statistische Verfahren(German), de Gruyter, Berlin, 2nd edition, pp.902, 1996.

Friedlander, S. K., Koch, W., and Main, H. H.: Scavenging of a coagulating fine aerosol by a coarse particle mode, J. Aerosol Sci., 22, 1-8, 1991 .

Hansson, H.-C., Martinsson, B. G., and Lannefors, H. O.: Long range aerosol transport in southern Sweden: An example of multivariate statistical evaluation methodology, Nucl. Instr. and Meth., 3, 483-488, 1984.

Harris, J.S. and Maricq, M. M.: Signature size distributions for diesel and gasoline engine exhaust particulate matter, J. Aerosol Sci., 32, 749-764, 2001.

Harrison, R. M., Jones, M., and Collins, G.: Measurements of the Physical Properties of Particles in the Urban Atmosphere, Atmos. Environ., 33, 309-321, 1999.

Heintzenberg, J.: Properties of the Log-Normal Particle Size Distribution, J. Aerosol Sci. Technol., 21, 46-48, 1994.

Hughes, L.S., Cass, G. R., Gone, J., Ames, M., and Olmez, I.: Physical and chemical characterization of atmospheric ultrafine particles in the Los Angeles area, Environ. Sci. Technol., 32, (9), 1153-1161, 1998.

Iversen, T.: Some statistical properties of ground level air pollution at Norwegian Arctic stations and their relation to large scale atmospheric flow systems, Atmos. Environ., 23, 2451-2462, 1989.

Kaimal, J.C. and Finnigan, J. J.: Atmospheric Boundary Layer Flows, Oxford University Press, New York, 1994.

Lam, G.C. K., Leung, D. Y.C., Niewiadomski, M., Pang, S. W., Lee, A. W. F., and Louie, P. K. K.: Street-level concentrations of 
nitrogen dioxide and suspended particulate matter in Hong Kong, Atmos. Environ., 33, 1-11, 1999.

Kuhlbusch, T. A. J., Hertlein, A.-M., and Schütz, L. W.: Sources, determination, monitoring, and transport of carbonaceous aerosols in Mainz, Germany, Atmos. Environ., 32, (32), 10971110, 1998.

Maricq, M. M., Podsiadlik, D. H., and Chase, R. E.: Gasoline Vehicle Particle Size Distributions: Comparison of Steady State, FTP and US06 Measurements, Environ. Sci. Technol., 33, 20072015, 1999.

Morawska, L., Thomas, S., Bofinger, N., Wainwright, D., and Neale, D.: Comprehensive characterization of aerosols in a subtropical urban atmosphere: particle size distribution and correlation with gaseous pollutants, Atmos. Environ., 32, 2467-2478, 1998.

Nilsson, E.D., Rannik, Ü., Kulmala, M., Buzorius, G., and O'Dowd, C. D.: Effects of continental boundary layer evolution, convection, turbulence and entrainment, on aerosol formation, Tellus, 53B, 441-461, 2001.

O’Dowd, C. D., McFiggans, G., Creasey, D. J., Pirjola, L., Hoell, C., Smith, M. H., Allan, B. J., Plane, J. M. C., Heard, D. E., Lee, J. D., Pilling, M. J., and Kulmala, M.: On the photochemical production of new particles in the coastal boundary layer, Geophys. Res. Lett., 26, 1707-1710, 1999.

Peters, A., Wichmann, H. E., Tuch, T., Heinrich, J., and Heyder, J.: Respiratory effects are associated with the number of ultrafine particles, Am. J. Respir. Crit. Care Med., 155, 1376-1383, 1997.

Pope, C. A. III and Dockery, D. W.: Epidemiology of particle effects, Air poll. Health, 31, 673-705, 1999.

Pueschel, R. F., van Valin, C. C., Castillo, R. C., Kadlecek, J. A., and Ganor, E.: Aerosols in Polluted versus Nonpolluted Air Masses: Long-Range Transport and Effects on Clouds, J. Climate and Applied Meteorology, 25, (12), 1908-1917, 1986.

Ristovski, Z.D., Morawska, L., Bofinger, N.D., and Hitchins, J.: Submicrometer and supermicrometer particulate emissions from spark ignition vehicles, Environ. Sci. Technol., 32, (24), 38453852, 1998.

Roorda-Knape, M. C., Janssen, N. A. H., de Hartog, J. J., van Vliet, P. H. N., Harssema, H., and Brunekreef, B.: Air pollution from traffic in city districts near major motorways, Atmos. Environ., 32, (11), 1921-1930, 1998.

Salcedo, R. L. R., Alvim Ferraz, M. C. M., Alves, C. A., and Martins, F. G.: Time-series Analysis of Air Pollution Data, Atmos. Environ., 33, 2361-2372, 1999.

Simpson, R. W.: A statistical analysis of particulate data sets in Brisbane, Australia, Atmos. Environ., 26B, 99-105, 1992.

von Storch, H. and Zwiers, F. W.: Statistical Analysis in Climate Research, University Press, Cambridge, pp. 484, 1999.

Statheropoulos, M., Vassiliadis, N., and Pappa, A.: Principal component and canonical correlation analysis for examining air pollution and meteorological data, Atmos. Environ., 32(6), 10871095, 1998.
Swietlicki, E., Puri, S., Hansson, H.-C., and Edner, H.: Urban air pollution source apportionment using a combination of aerosol and gas monitoring techniques, Atmos. Environ., 30(15), 27952809, 1996.

Tennekes, H. and Lumley, J. L.: A First Course in Turbulence, The MIT Press, Cambridge, Massachusetts, London, pp. 300, 1974.

Tuch, T., Brand, P., Wichmann, H.E., and Heyder, J.: Variation of Particle Number and Mass Concentration in Various Size Ranges of Ambient Aerosols in Eastern Germany, Atmos. Environ., 31, 4293-4197, 1997.

Väkevä, M., Hämeri, K., Kulmala, M., Lahdes, R., Ruuskanen, J., and Lahtinen, T.: Street level versus rooftop Concentrations of submicron aerosol particles and gaseous pollutants in an urban street canyon, Atmos. Environ., 33, 1385-1397, 1999.

van der Zee, S.C., Hoek, G., Harssema, H., and Brunekreef, B.: Characterization of particulate air pollution in urban and nonurban areas in the Netherlands, Atmos. Environ., 32, (21), 37173729, 1998.

Wåhlin, P., Palmgren, F., v. Dingenen, R., and Raes, F.: Pronounced decrease of ambient particle number emissions from diesel traffic in Denmark after reduction of the sulfur content in diesel fuel, Atmos. Environ., 35, 3549-3552, 2001.

Weber, R.J., McMurry, P.H., Mauldin III, R.L., Tanner, D. J., Eisele, F.L., Clarke, A.D., and Kapustin, V.N.: New particle formation in the remote troposphere: A comparison of observations at various sites, Geophys. Res. Lett. 26(3), 307-310, 1999.

Wehner, B.: Particle formation in the urban atmosphere, $\mathrm{PhD}$ thesis, Univ. Leipzig, pp. 117, 2000.

Wehner, B., Birmili, W., Gnauck, T., and Wiedensohler, A.: Particle number size distributions in a street canyon and their transformation into the urban-air background: Measurements and a simple model study, Atmos. Environ., 36, 2215-2223, 2002.

Whitby, E. R. and P. H. McMurry, Modal Aerosol Dynamics Modelling, J. Aerosol Sci. Technol., 27, 673-688, 1997.

Wichmann, H.E., Spix, C., Tuch, T., Wölke, G., Peters, A., Heinrich, J., Kreyling, W. G., and Heyder, J.: Daily mortality and fine and ultrafine particles in Erfurt, Germany Part I: Role of particle number and particle mass, Health Effects Institute Report No. 98, 2000.

Wiedensohler, A., Covert, D. S., Swietlicki, E., Aalto, P., Heintzenberg, J., and Leck, C.: Occurrence of an ultrafine particle mode less than $20 \mathrm{~nm}$ in diameter in the marine boundary layer during Arctic summer and autumn, Tellus, 48B, 213-222, 1996.

Wolff, G. T., Morrissey, M. L., and Kelly, N. A.: An Investigation of the Sources of Summertime Haze in the Blue Ridge Mountains Using Multivariate Statistical Methods, J. Clim. Appl. Meteorol., 23, (9), 1333-1341, 1984.

Woo, K.S., Chen, D. R., Pui, D. Y.H., and McMurry, P.H.: Measurement of Atlanta Aerosol Size Distributions: Observation of ultrafine particle events, Aerosol Science and Technology, 34, 75-87, 2001. 